science. While that would be highly desirable in itself it would not be easy to achieve. At the same time, a demand for biologists, as distinct from botanists and zoologists, would have repercussions on the universities in Britain which in the long run would be likely to be salutary.

As an appendix to his article, Dr. Edney has drawn up a three-year curriculum in biology to pass-degree standard, which may be obtained on application.

${ }^{1}$ Biology and Human Affairs, 13, 111 (1948). (British Social Hygiene Council (Inc.), Tavistock House North, London, W.C.1.)

\section{EDUCATION IN MYCOLOGY}

$\mathrm{T}$ E first duty of Prof. A. E. Muskett as president of the British Mycological Society for the ensuing year was to preside at the discussions of the Society on "Mycological Education" at its meeting on January 31. In the first paper of the session, "The Society and Mycological Education", Dr. G. C. Ainsworth reminded us that mycological education is implicit in many of the activities of the Society, not the least of these being the annual foray where amateur and professional mycologists forgather for a week of intensive study of fungi collected on daily excursions. This club meeting has done much to keep alive the "tradition of species". By its report on "The Need for Encouraging the Study of Systematic Mycology in England and Wales" printed, but not published, in 1944, and by its subsequent report on "The Teaching of Mycology" printed in 1946, but again not published, the Society focused attention on the dearth of trained mycologists and of systematists in particular, and on the need for detailed consideration of, and early action to secure, the adequate training of mycologists in the diverse fields in which present-day conditions require their services. The discussion afforded the exchange of views on the question of mycological education between mycologists of widely different interests.

Admitting that the topic of education for a specific career is always a difficult subject to review, Dr. W. G. Keyworth, in presenting the case of "Mycology for the Plant Pathologist", outlined the present course of training of a plant pathologist during the study for his initial degree. Here mycology is treated in the same way as other aspects of botany, emphasis being placed on those families showing features of taxonomic interest. Research on a specific and often rather limited field of investigation usually followed before the plant pathologist embarked on his career as an adviser or as a research worker. Valuable as the present system is, Dr. Keyworth considers that continued study of general mycology after taking a first degree is of paramount importance. This study should not only include pathogenic but also saprophytic fungi, should involve a consideration of the Fungi Imperfecti, should deal with the study of the fungi in vivo and in vitro, and should include an adequate treatment of the taxonomy of fungi. Thereafter, and before commencing professional duties, the plant pathologist destined to become an adviser might gain experience in field recognition of diseases at an advisory centre, and the plant pathologist following research work as a career might gain experience in research methods and technique as applied to pathogenic fungi. Dr. Keyworth concluded by suggesting that postgraduate courses should be instituted, and that these might well lead to a diploma or to a higher degree which could be the accepted hallmark of a sound preliminary training.

The absence of courses which completely cover the requirements of industrial microbiologists was emphasized by Dr. F. D. Armitage during his paper on "Mycology and the Industrial Microbiologist". Certain microfungi are studied as examples of moulds in courses of bacteriology, but to obtain a working knowledge of systematic mycology the microbiologist must depend on private reading of current literature -a task almost impossible without some expert guidance. He suggested that the Society might use its influence to create a school of mycology which would develop a course suitable for mycologists in industry, paying particular attention to mycologica technique, to the maintenance of culture collections, to the sampling methods applied to mycological analysis, to the study of inhibitors and to the principles of taxonomy. Failing this, the Society might organise, and later publish, a series of lectures designed for those commencing the study of microfungi. He was certain sound mycological education is a vital problem at the present time.

During his paper on "Mycology for the Medical Practitioner", Dr. I. Martin Scott suggested that the practitioner's lack of intimate knowledge of this branch of science was due to the overloaded curri. culum of the present degree and to the lack of facilities for graduate studies. Normally only a single lecture is devoted to pathogenic fungi during undergraduate courses, and in public health studies only a short course on medical my cology is available. The remedies are obvious: future undergraduates should receive systematic instruction in mycology, as they do now in bacteriology, and graduate schools for further study and for research should be estab. lished. Close collaboration between medical practitioners and mycologists is essential in this field.

The case for "Mycology for the Amateur" was ably presented by Mr. J. M. B. King, who stated that the Society offers the best place for the amateur, who takes his mycology seriously, to obtain that advice and guidance which the personal experience of its members, obtained by the study of fungi in the field, can give. The Society could further aid the amateur by sponsoring books written in as nontechnical a language as possible containing adequate keys, colour charts and fully documented glossaries of necessary technical terms. $\mathrm{He}$ believed that periodic publication in its Transactions of articles dealing with the fundamental features of fungal structure, with the principles of classification and with taxonomic problems would be appreciated. Efforts might be made to increase the number of forays and of meetings of general interest, some of which might be demonstrations of named specimens similar to that recently held.

Dealing with "Mycology and the Universities", Prof. C. G. C. Chesters stated that the orthodox training in mycology was obtained within the scope of an honours degree in botany, the fungi being treated as a section of the Thallophyta. He believed that the fungi should be removed from this phylum and might be treated as a separate discipline within the confines of botany. Since mycology must be based on a knowledge of the living fungus, collection of material in the field must play a large part in any well-balanced course, which must also include the study of the physiology, the genetics and the technique of cultivation of fungi in vitro. Graduate 
studies of a more detailed character should precede research investigations. Suggesting that there might well be a place for a more heterodox training in mycology, he outlined a course for an honours degree in which, during the years subsequent to intermediate studies, chemistry, botany (exclupling the fungi) and mycology should be studied as parallel courses for two years and should be followed by a final year devoted entirely to mycology. The principles of bacteriology should be introduced during initial studies in mycology.

Mr. L. M. J. Kramer, speaking on "Mycology in Relation to Schools", said that it was mainly. during study for the higher school certificate or the university entrance examinations that the implications of mycology and the future openings for those able to undertake the necessary training could be presented to the scholars. Teachers would appreciate articles on simple laboratory exercises, on current trends in mycological studies and on openings for mycologists, as well as details of the necessary training, in such journals as the School Science Review.

In the discussion which followed the papers, Dr. Wilkins supported the separation of mycology from botany and hoped that the Society might influence university opinion to recognize mycology as a special subject for study. Dr. J. Ramsbottom considered that Mr. 'Kramer's suggestion that there was a lack of trained science teachers raised an important topic and stated that, while he would not enter the argu. ment for or against mycology being taught as a discipline separate from botany, it was essential to realize the great development of mycology during the past few years. Progress in teaching industrial mycology is slow at present but nothing can stop the development of this line of study. The hope for medical mycology lies in the fullest co-operation of the mycologist and practitioner. $\mathrm{He}_{\mathrm{e}}$ believed the possibility of a bulletin for amateurs sponsored by the Society might be considered. Mr. Large pointed out that plant pathologists had to be more than professional mycologists and that there was a decided lack of good drawings and simple descriptions of fungi. Dr. Wood was against any separation of botany and mycology and emphasized that plant pathologists had to be botanists. Dr. Cook believed that botany was outgrowing itself, that the difference between green plants and fungi was fundamental and that there was a place for a specialized mycology course following a general degree with botany as one of its subjects. Dr. Prentice deplored early specialization and considered that specialized graduate studies should follow a liberal first degree course. Dr. Keyworth thought a degree in botany was of fundamental value and that the necessity of a lengthened period of training by the introduction of postgraduate courses must be considered.

Reviewing the papers and the subsequent discus. sion, Prof. C. T. Ingold reminded members that the Society had developed from a field club to assume the lead in mycological thought in Great Britain without losing the essential characters of a field club. Its reports demonstrate its vital interest in adequate provision for mycological education and its encour. agement of taxonomic studies. Believing that the greatest weight should be placed on special postgraduate courses, Prof. Ingold referred to the present contribution of individual departments and suggested that industrial mycology might be established at technical colleges and, when medical education is reorganised, a place should be found for medical mycology. He considered that fungi should be treated outside the Thallophyta and that a reunion of bacteriology and mycology would be advantageous. Additional literature on the systematic side is urgently required. Prof. Ingold concluded by sug. gesting that the Committee of the Society which dealt with the teaching of mycology might continue its deliberations in the light of these discussions and might consider the institution of special series of lectures on mycological topics.

Charles G. C. Chesters

\section{A TRIBUTE OF INDUSTRY TO SCIENCE}

A SPECLAL meeting of the Industrial Research A Committee of the Federation of British Industries was held at the Royal Institution on March 19 in honour of Sir Robert Robinson and Sir Edward Appleton, who received the Nobel Prizes in 1947 for Chemistry and for Physics, respectively. Sir Frederick Bain, who presided, pointed out that not since 1904 had the prizes for chemistry and physics both come to Great Britain undivided and undisputed, although since 1901 Britain has had no less than thirty-six Nobel Prize awards in the five different categories. He described the meeting as a whole-hearted demonstration by British industry of pleasure at this authoritative recognition of the work of Robinson and Appleton, who now shared the distinction of Sir William Ramsay and Lord Rayleigh in 1904, and also a sincere recognition of what industry owes to science as represented by them. Sir Frederick said that he had been privileged to work intimately both with Sir Robert and Sir Edward, and that during the War we had learned how the scientist and industrialist could work together for a common objective. Great scientists could be effective men of affairs, and through the example and devotion of men like Robinson and Appleton, Britain had become, in war as in peace, not only a country of the questing mind and free experimental approach but also, above all, a place for sharing ideas, improvisation in emergency and effectiveness in application of scientific work.

Sir Robert Robinson, in a brief address on the "Scope of Organic Chemistry", referred to the way in which contact with industry has enriched our knowledge of organic chemistry, to the great stimulus which the study of complex molecules has given to organic chemistry and conversely to the contribution of organic chemistry to the development of the biological sciences. After referring to the opportunities for co-operation between different scientific workers afforded by such fields as catalysis and polymerization, and to the evolution in the last twenty years of the industry of aliphatic chemicals, Sir Robert stressed the national importance of organic chemical industry. In this connexion he urged the extension of facilities for research in organic chemistry and stressed the function of the universities in training research workers. For that function to be discharged effectively, parallel with the growth of industrial research laboratories and the expansion of technical colleges, there should be higher salaries for science teachers and the enlarging and modernization of university departments.

Sir Edward Appleton's address, "The Scientist in Industry", discussed in greater detail some aspects 